\title{
INVESTIGATING SEASONAL FEATURES OF ELECTRON TEMPERATURE ENHANCEMENT REGIONS IN THE SUBAURORAL IONOSPHERE
}

\author{
A.Yu. Gololobov \\ M.K. Ammosov North-Eastern Federal University, \\ Yakutsk,Russia,golart87@gmail.com
}

\author{
I.A. Golikov \\ Yu.G. Shafer Institute of Cosmophysical Research and Aeronomy, \\ Yakutsk,Russia,gia2008@mail.ru
}

\begin{abstract}
The electron temperature enhancement is known to occur in the main ionospheric trough during geomagnetic disturbances. In this paper, we study features of the formation of the electron temperature $\left(T_{\mathrm{e}}\right)$ enhancement in the subauroral ionosphere by comparing results of the numerical simulation with measurements of $T_{\mathrm{e}}$ onboard the CHAMP satellite under moderate geomagnetic activity conditions. It is shown that depending on the terminator position and universal time (UT), the location of the enhanced $T_{\mathrm{e}}$ regions in the subauroral ionosphere varies in different seasons. So, in winter ring-shaped and sickle-shaped regions can be formed,
\end{abstract}

whereas during the equinox and summer periods sickleshaped regions of different lengths and clarity are generally observed.

Keywords: subauroral ionosphere, numerical model, electron temperature enhancement, seasonal features, ring current, ring-shaped and sickle-shaped regions, CHAMP.

\section{INTRODUCTION}

The authors of [Brace et al., 1982; Kofman, 1984; Prölls, 2006] have found effects of electron temperature enhancement in the subauroral ionosphere from experimental data. Prölls [2006] has studied an electron temperature $T_{\mathrm{e}}$ enhancement, using DE-2 satellite data. It has been found that the enhanced $T_{\mathrm{e}}$ region spatially coincides with the position of the main ionospheric trough (MIT). The numerical simulation of the thermal regime of the high-latitude ionosphere, including the subauroral one, has been studied in a number of papers [Klimenko et al., 1991; Mingaleva, Mingalev, 1992; David et al., 2011; Mingaleva, Mingalev, 1996; Prölls, 2006; Schunk et al., 1986], which examined causes of the formation of enhanced temperature regions. The enhanced $T_{\mathrm{e}}$ has been shown to be related to downward heat fluxes, electric fields, and lower electron density $n_{e}$ in MIT. In [Büchner, Lehmann H.-R. 1983; Krymsky, 1990; Cole, 1965; Prölls, 2006], the authors have suggested that a possible cause of enhanced $T_{\mathrm{e}}$ in the subauroral ionosphere can be the ring current, which increases during disturbances. The heat, generated by ring current particles at heights of several Earth radii, due to the high thermal conductivity of electron gas can be transferred down along geomagnetic field lines into F-layer heights, thus causing $T_{\mathrm{e}}$ to rise.

Our purpose here is to study features of the formation of enhanced $T_{\mathrm{e}}$ regions in the subauroral ionosphere in different seasons, using a numerical model of the high-latitude ionosphere and CHAMP satellite data.

\section{MODEL OF THE HIGH-LATITUDE IONOSPHERE}

Calculations have been made using a model of the high-latitude ionospheric F-region in Euler variables. The model accounts for the mismatch between the geo- graphic and geomagnetic poles [Golikov et al., 2016]. Here we give its brief description. The density of atomic oxygen ions $n\left(\mathrm{O}^{+}\right)$, electron $T_{\mathrm{e}}$ and ion $T_{\mathrm{i}}$ temperatures are determined from the numerical solution of the system of three-dimensional unsteady-state equations consisting of continuity equations for $\mathrm{O}^{+}$ions, thermal conductivity for electrons and ions in the height range from 120 to $500 \mathrm{~km}$. In this range, we can assume the quasineutrality condition $n_{\mathrm{e}} \approx n\left(\mathrm{O}^{+}\right)$. Then, we specify the electron gas cooling rate for the interaction with ions and neutral particles as in [David et al., 2011; Schunk, Nagy, 1978]. The temperature and density of neutral components were calculated by the thermosphere model NRLMSISE-00 [Picone et al., 2002]. The magnetospheric convection electric field is specified using Heppner's A model [Heppner, 1977]. To calculate the corpuscular ionization rate, we employ the auroral precipitation model [Vorobjev et al., 2013], and the function of ion formation by precipitated particles is determined from the results obtained by Fang et al. [2008]. Wave ionization rates for large solar zenith angles $\left(\chi>75^{\circ}\right)$ are calculated as in [Chapman, 1931].

The algorithm for solving the system of modeling equations as well as their boundary conditions have been examined in [Golikov et al., 2012, 2016]. For the numerical solution of three-dimensional differential equations, we use the total-approximation method [Samarsky, 1977], which reduces the solution of three-dimensional differential equations to the successive solution of a system of onedimensional equations. Next, we utilize the finite difference approximation and then reduce it to the three-point scheme, which is solved by the tridiagonal matrix algorithm. As the initial condition for $n\left(\mathrm{O}^{+}\right)$we use the simple Chapman layer and equate electron and ion temperatures to the neutral gas temperature $\left(T_{\mathrm{e}}=T_{\mathrm{i}}=T_{\mathrm{n}}\right)$. The calculations are made at $\Delta r=10 \mathrm{~km}, \Delta \theta=2^{\circ}, \Delta \varphi=10^{\circ}, \Delta t=2 \mathrm{~min}$. On a 
personal computer with a $2400 \mathrm{MHz}$ processor and 4000 $\mathrm{Mb}$ random-access memory, it takes approximately $30 \mathrm{~min}$ to find a periodic solution.

\section{RESULTS OF MODEL CALCULATIONS}

Figure 1 and 2 show $n_{\mathrm{e}}$ and $T_{\mathrm{e}}$ distributions at a height of $300 \mathrm{~km}$ for different seasons at 05 and 17 UT in the local time coordinates (longitude) - the geographic latitude when we specify the downward heat flux $P=-5 \cdot 10^{9} \mathrm{eV} \mathrm{cm}^{-2} \mathrm{~s}^{-1}$, which is formed during moderate geomagnetic disturbances $\left(K_{\mathrm{p}} \approx 3\right)$ by the ring current [David et al., 2011] at $58^{\circ}-62^{\circ}$ geomagnetic latitudes. Here, $n_{\mathrm{e}}$ and $T_{\mathrm{e}}$ are given in the form of isolines. Concentric circles correspond to geographic latitudes with a step of $10^{\circ}$. Numerals near the outer circle mark the local time; in brackets is the geographic longitude. The dashed line is the position of the terminator at a zenith angle $\chi=90^{\circ}$. The point with two mutually perpendicular lines is the geomagnetic pole. Arrows indicate electron velocities caused by the electric field of magnetospheric origin. The dash-dot circle shows the plasmapause position, which corresponds to the equatorial boundary of the magnetospheric convective region, (specified by Heppner's A model [Heppner, 1977].

At 17 UT, the geomagnetic pole was close to the local noon, and the plasmapause was partially on the dayside. Hence, the magnetospheric convection and the transfer of the daytime ionization to the nightside cause the tongue of ionization to appear. Behind the tongue on the nightside, there is a decrease in $n_{\mathrm{e}}$ identified with the subauroral ionosphere and MIT [Bryunelli, Namgaladze, 1988] (Figure 1, $a$ ). Then, in the subauroral ionosphere, where the downward heat flux $P$ has been set $P$, a sickle-shaped enhanced $T_{\mathrm{e}}$ region is formed which coincides in position with MIT, where $T_{\mathrm{e}}$ is 3000 $\mathrm{K}$ and higher. At $05 \mathrm{UT}$, the geomagnetic pole is near the midnight meridian, and the convective region is on the nightside (Figure 1, b). As a result, the tongue of ionization is separated from the daytime ionosphere, thus leading to the formation of a daytime trough between the terminator and the convective region. Thus, the $n_{\mathrm{e}}$ trough in the latitude profile is formed behind the convective region in the entire LT interval, where due to the heat flux $P$ in the subauroral ionosphere there appears a ring-shaped enhanced $T_{\mathrm{e}}$ region, where $T_{\mathrm{e}}$ is $2000 \mathrm{~K}$ and higher (Figure 2, b).

Under vernal equinox conditions, the terminator shifts down to the 06-18 LT line (Figure 1, $c, d$ ). The convective region is partly on the daylight side, and unlike winter conditions there is no daytime trough at 05 UT. In the $T_{\mathrm{e}}$ distribution, the effect of the downward heat flux $P$ in the subauroral ionosphere gives rise to a sickle-shaped enhanced $T_{\mathrm{e}}(>2000 \mathrm{~K})$ region at $\sim 22-07$ LT both at $17 \mathrm{UT}$ and at $05 \mathrm{UT}$ (Figure 2, $c, d$ ). In this case, the region is more pronounced and is located at lower latitudes at $05 \mathrm{UT}$ than at 17 UT due to the mismatch between the poles.

Then, under summer solstice conditions the terminator moves down and the entire high-latitude ionosphere at 17 UT is predominantly on the dayside, thus significantly reducing the probability of $T_{\mathrm{e}}$ enhancement at subauroral latitudes (Figure 2,e). This season is characterized by the fact that the plasma heating by the heat flux $P$ causes $T_{\mathrm{e}}$ to rise in the subauroral ionosphere only at 05 UT, when due to the mismatch between the poles a part of the subauroral ionosphere is on the nightside (Figure 2, $f$ ).

We can conclude that the effect of the downward heat flux $P$ leads to the formation of enhanced $T_{\mathrm{e}}$ regions in the subauroral ionosphere on the nightside. In this case, configurations of the enhanced $T_{\mathrm{e}}$ regions in different seasons differ and depend on the universal time. So, in winter at $05 \mathrm{UT}$ the $T_{\mathrm{e}}$ enhancement is ringshaped, coinciding with the position of the $n_{\mathrm{e}}$ trough; and at 17 UT in other seasons it is sickle-shaped with different lengths and clarity.

\section{COMPARISON WITH CHAMP DATA}

The CHAMP satellite was launched on July 15, 2000 with an orbit inclination of $87.3^{\circ}$. It measured $n_{\mathrm{e}}$ and $T_{\mathrm{e}}$ at $310 \div 456 \mathrm{~km}$ until 2009 [Reigber et al., 2002; Xiong et al., 2013]. The main feature of this satellite is that its orbital plane due to Earth's nonsphericity precesses around Earth and for about 130 days, shifting, passes all local time sectors. This allows us to use CHAMP data to study spatial and temporal features of the formation of enhanced $T_{\mathrm{e}}$ regions. Here we examine space-time distributions of locations of enhanced $T_{\mathrm{e}}\left(T_{\mathrm{e}}\right.$ peaks) in the subauroral ionosphere we have constructed from CHAMP data [http://isdc-old.gfz-potsdam.de] for different seasons and compare them with the results of model calculations.

Figure 3 shows typical latitudinal profiles of $n_{\mathrm{e}}$ and $T_{\mathrm{e}}$ for three seasons under moderate geomagnetic activity. To the right in the equatorial plane, the solid line shows CHAMP trajectories, and arrows on the lines indicate the satellite's motion direction. Numerals 1 and 2 on the latitudinal profile and respectively on the satellite trajectory mark the positions of the subauroral ionosphere, determined from the equatorial boundary of the auroral ionization and latitudinal position of the $n_{\mathrm{e}}$ trough; bold arrows show the positions of $T_{\mathrm{e}}$ peaks in the subauroral ionosphere.

Figure 3, a shows that in the latitude profile the electron density behind the terminator on the nightside begins to fall sharply due to the lack of effective ionization sources, forming a daytime ionization trough in the subauroral ionosphere (1), and in the post-midnight sector the satellite crosses MIT (2). In the vicinity of the daytime trough and MIT, we observe the $T_{\mathrm{e}}$ peaks (thick arrows) exceeding 2500 and $6000 \mathrm{~K}$ respectively. In the latitudinal profiles obtained for equinoxes and summer (Figure 3,b,c) due to the fact that the subauroral ionosphere is on the daylight side, the daytime trough and the $T_{\text {e }}$ peaks are absent on the dayside. Positions of the subauroral ionosphere on the dayside are shown along the equatorial boundary of auroral ionization (1). Figure $3, b, c$ shows that on the nightside there is 


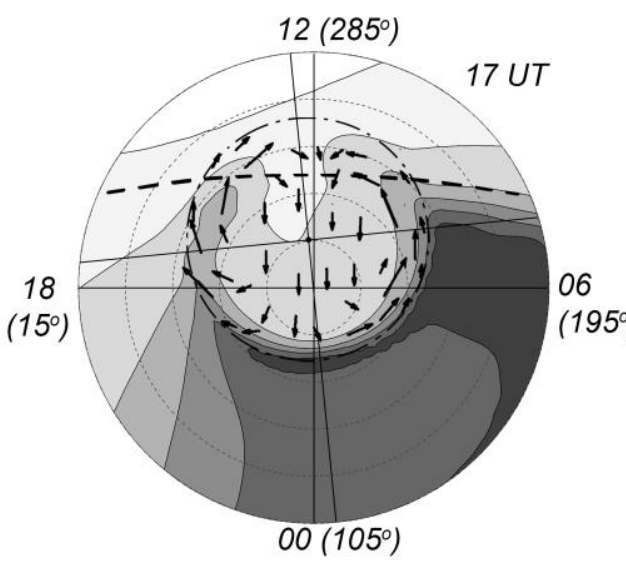

$a$
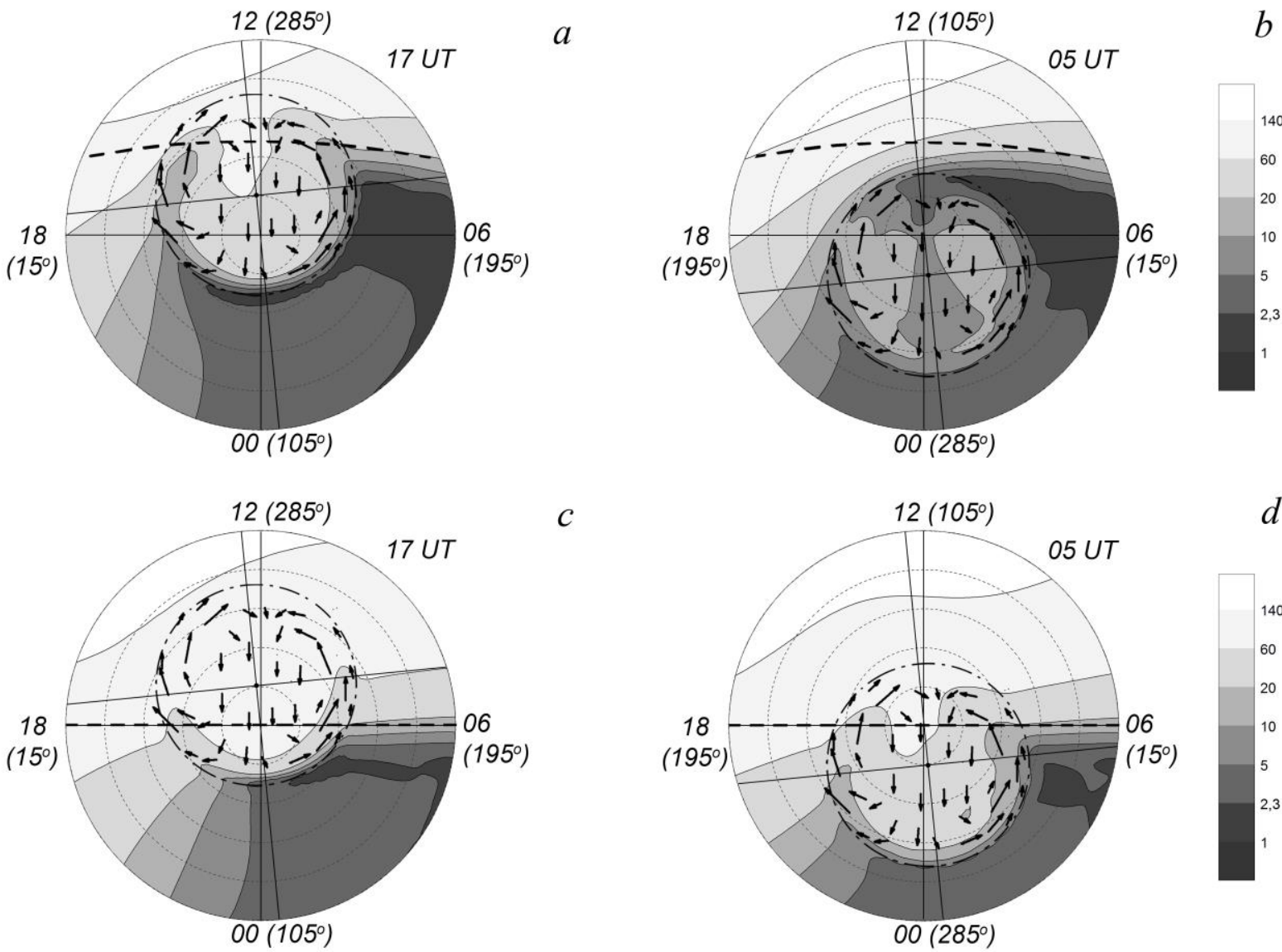

$c$

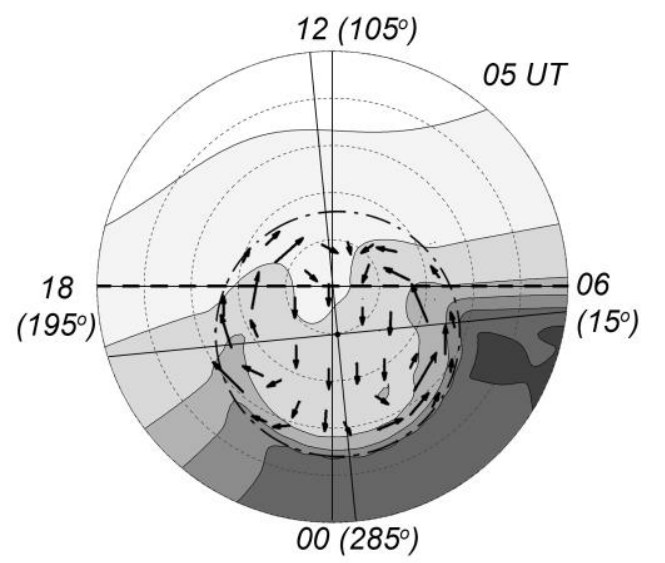

$d$
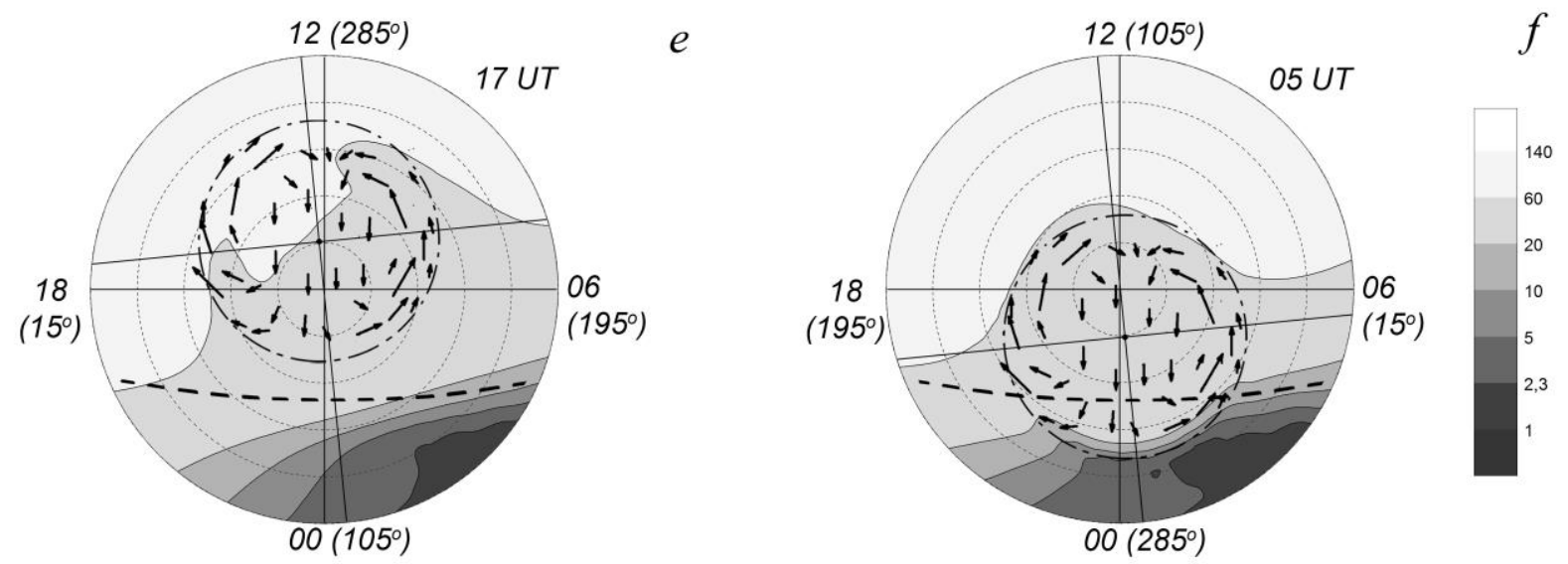

Figure 1. Calculated electron density distributions $\left(10^{4} \mathrm{~cm}^{-3}\right)$ at a height of $300 \mathrm{~km}$ at 05 and $17 \mathrm{UT}$ for winter solstice $(a, b)$, vernal equinox $(c, d)$, and summer solstice $(e, f)$

MIT with well-defined equatorial and polar walls (2), where $T_{\mathrm{e}}$ is increased (as high as $\sim 2000 \mathrm{~K}$ ). The Figure shows that in the nightside subauroral ionosphere during these seasons we can observe both MIT and $T_{\mathrm{e}}$ peaks.

In the equinoctial months, $T_{\mathrm{e}}$ peaks are localized predominantly on the nightside, forming a sickle-shaped region (Figure $4, c, d$ ), with $T_{\mathrm{e}}$ peaks at 04-07 UT recorded at lower latitudes (Figure $4, d$ ) than those at 1619 UT, as in model calculations due to the mismatch between the poles (Figure 2,d).

During summer months (June, July), the number of
$T_{\mathrm{e}}$ peaks decreases (hence the zone clarity). They are mainly located on the nightside at 04-07 UT, where the sickle-shaped zone is more pronounced than at 16-19 UT (Figure $4, f$ ), where the subauroral ionosphere is on the daylight side.

The comparison between the results of model calculations (Figure 2) and CHAMP measurements of $T_{\mathrm{e}}$ (Figure 4) shows good qualitative agreement in both the geometry of the enhanced $T_{\mathrm{e}}$ regions at different UT moments and the seasonal characteristics associated with illumination conditions of the subauroral ionosphere in different seasons. 


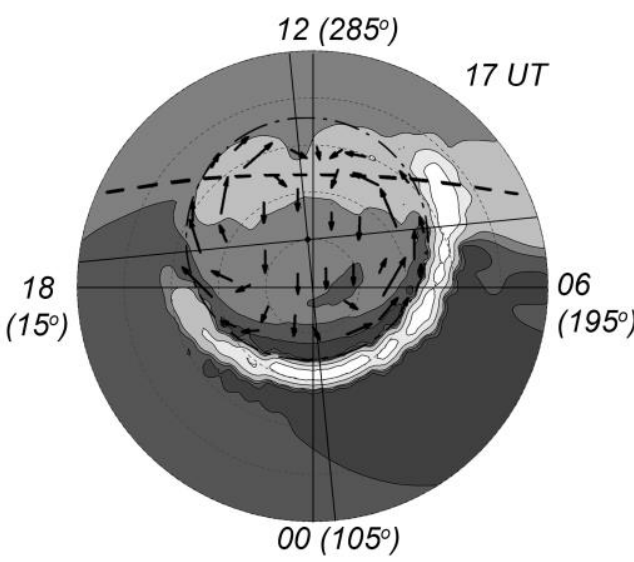

$a$

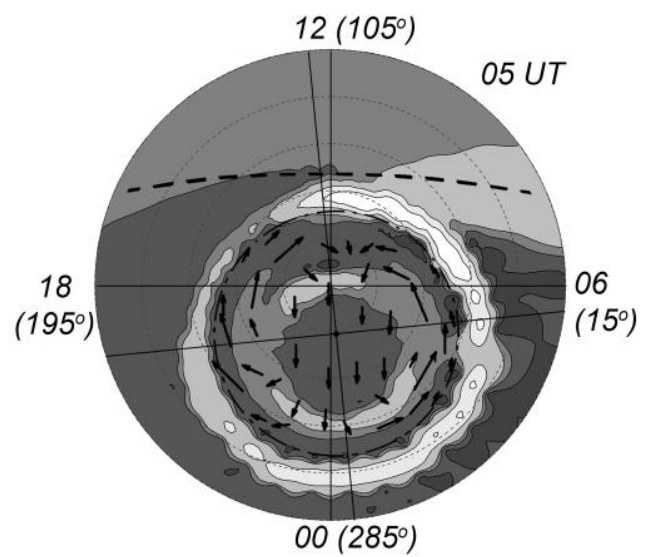

$b$

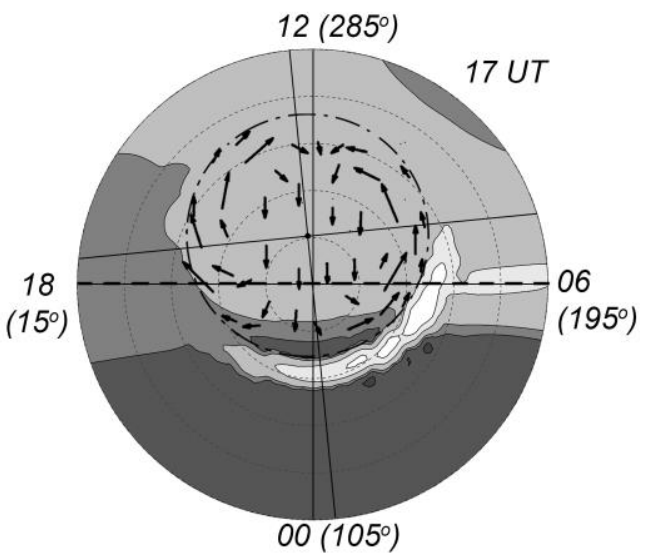

$c$

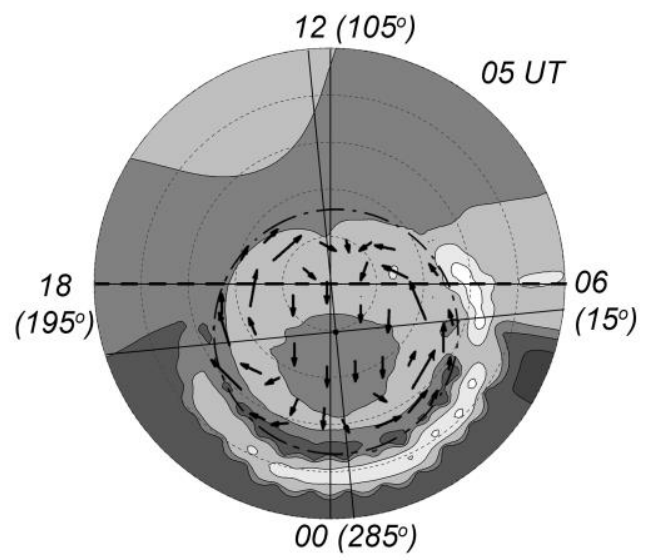

$d$
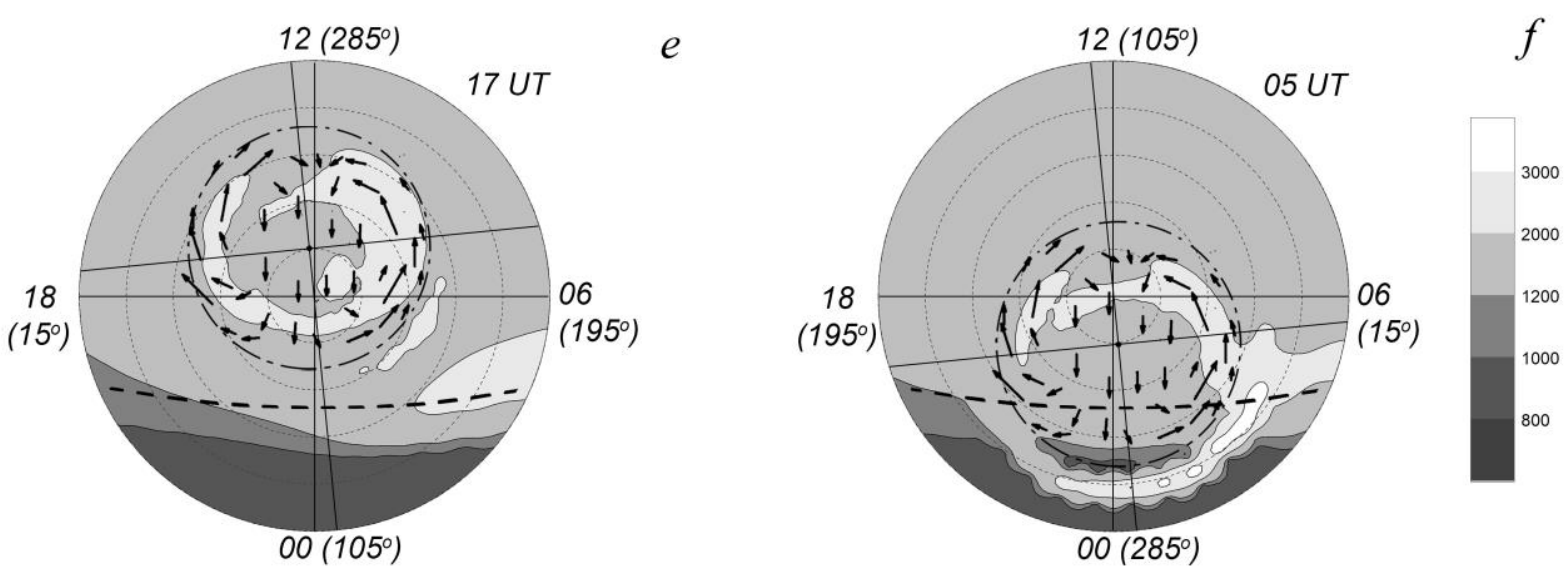

Figure 2. Calculated electron temperature distributions (in $\mathrm{K})$ at $300 \mathrm{~km}$ at 05 and $17 \mathrm{UT}$ for the winter solstice $(a, b)$, vernal equinox $(c, d)$, and summer solstice $(e, f)$ 

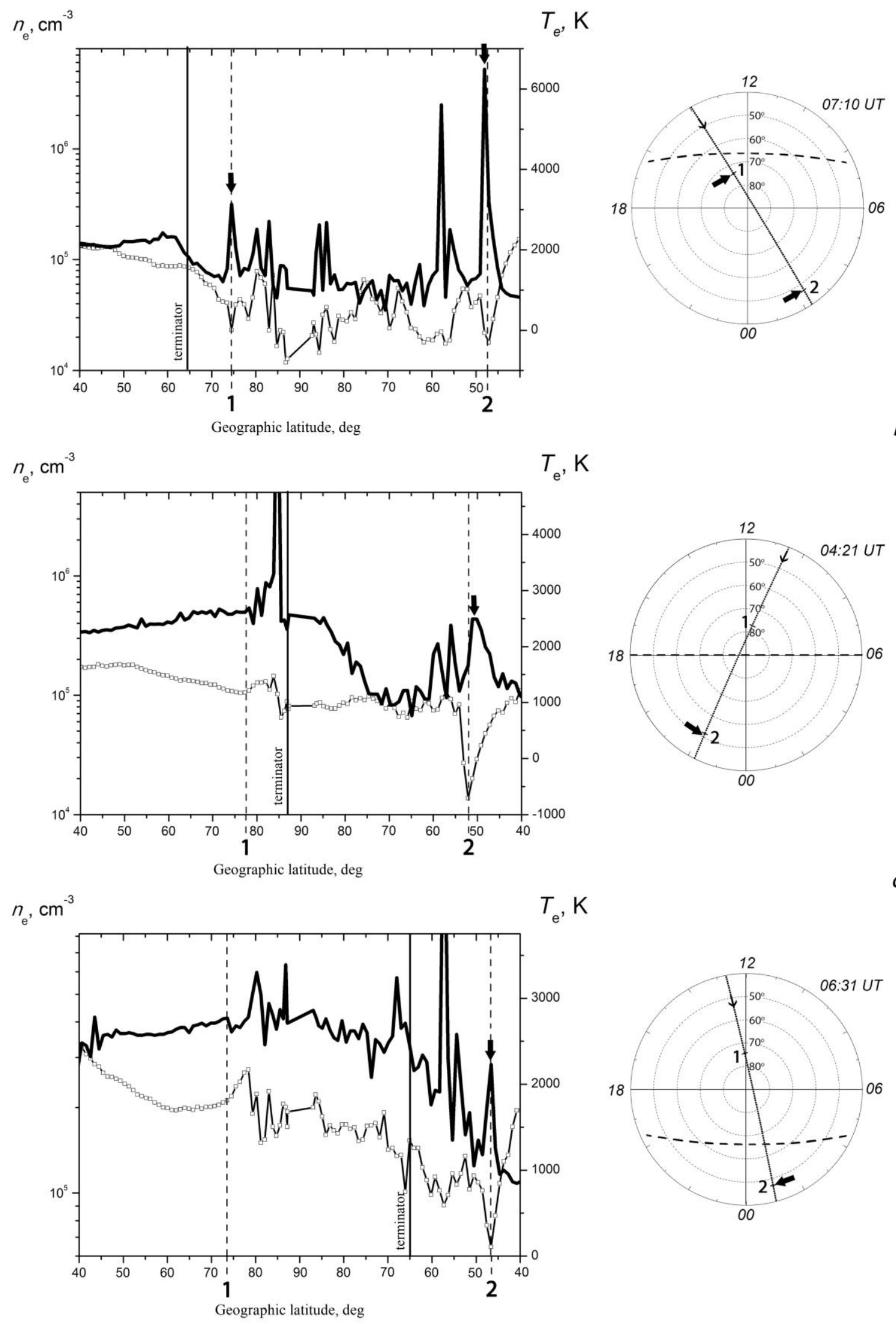

Figure 3. Latitudinal temperature and electron density profiles (right) and CHAMP trajectories (left) obtained for winter (a), equinoxes $(b)$, and summer $(c)$ at $K_{\mathrm{p}} \approx 3$ 


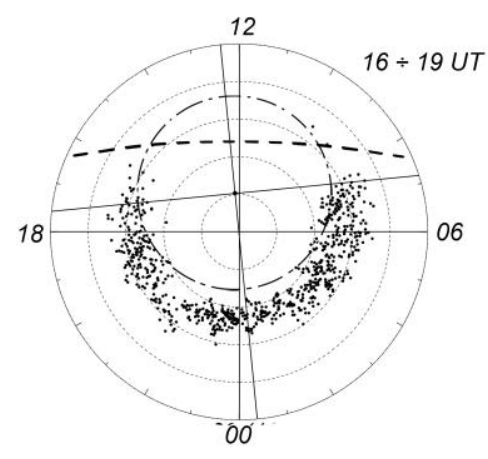

$a$

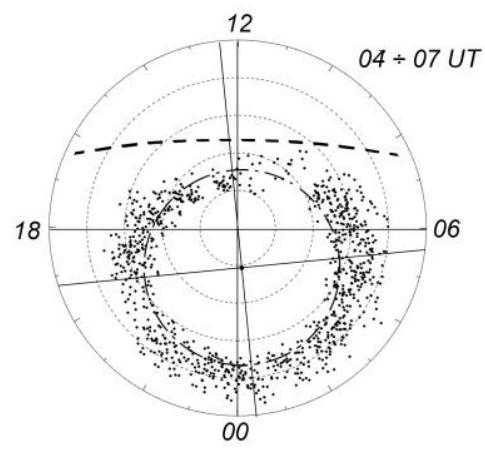

$b$

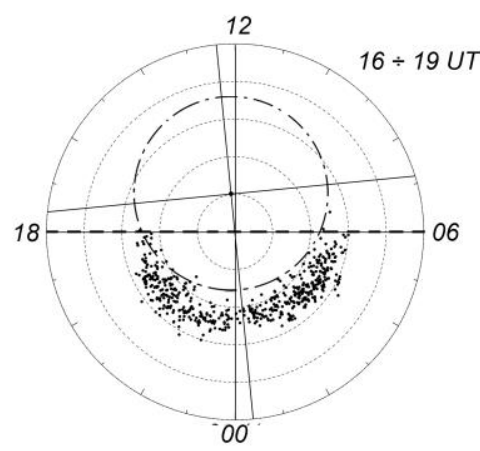

$c$

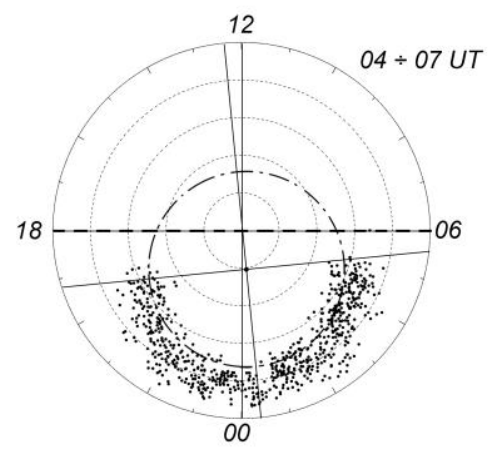

$d$
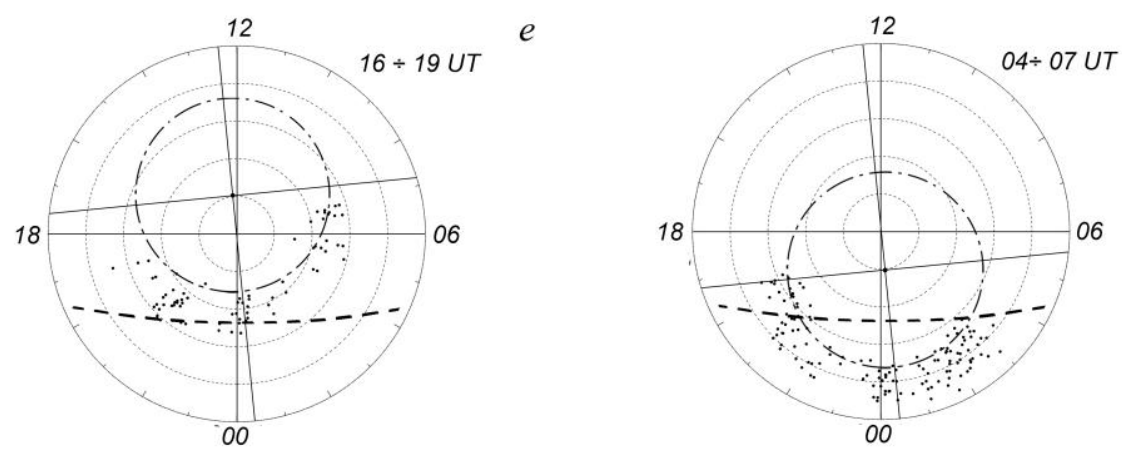

$f$

Figure 4. Spatial distribution of $T_{\mathrm{e}}$ peaks (dots) in local time - latitude coordinates derived from CHAMP data at 16-19 UT and 04-07 UT for winter $(a, b)$, equinoxes $(c, d)$, and summer $(e, f)$

\section{CONCLUSION}

The performed study of seasonal characteristics of the formation of enhanced electron temperature regions in the subauroral ionosphere under moderate geomagnetic activity and heat flux from the plasmasphere based on the comparison between numerical simulation results and CHAMP data has shown the following.

- Configurations of the enhanced $T_{\mathrm{e}}$ regions in the subauroral ionosphere at different seasons vary considerably and depend on the position of the terminator and on the universal time due to the mismatch between the geographic and magnetic poles.

- In winter at 04-07 UT in the subauroral ionosphere, a ring-shaped enhanced $T_{\mathrm{e}}$ region can be formed; and at $17 \mathrm{UT}$, a sickle-shaped region.

- In equinoxes and summer, enhanced $T_{\mathrm{e}}$ regions in the subauroral ionosphere are sickle-shaped with different lengths and clarity.

This work was supported by RFBR grant No. 18-45140037r_a and No. 18-45-140003r_a.

\section{REFERENCES}

Brace L.H., Theis R.F., Hoegy W.R. A global view of $\mathrm{F}$ region electron density and temperature at solar maximum. Geophys. Res. Lett. 1982, vol. 9, no. 9, pp. 989-992. DOI: 10.1029/GL009i009p00989.

Bryunelli B.E., Namgaladze A.A. Physics of the Ionosphere. Moscow, Nauka Publ., 1988, 528 p. (In Russian).

Büchner J., Lehmann H.-R. On possible mechanism of magnetospheric origin of temperature peak in the main ionospheric trough. Physical Processes in Main Ionospheric Trough Region. Praha: Geofyz. Ustav CSAV, 1983, 203 p. (In Russian).

Chapman S. The absorption and dissociative of ionizing effect of monochromatic radiation in an atmosphere on a rotation Earth. Proc. Phys. Soc. 1931, vol. 43, no. 5, pp. 483-501. DOI: 10.1088/0959-5309/43/5/302.

Cole K.D. Stable auroral red arcs, sinks for energy of Dst main phase. J. Geophys. Res. 1965, vol. 70, no. 7, pp. 1689 1709. DOI: $10.1029 / J Z 070 i 007 p 01689$.

David M., Schunk R.W., Sojka J.J. The effect of downward electron heat flow and electron cooling processes in the high-latitude ionosphere. J. Atm. Solar-Terr. Phys. 2011, vol. 73, no. 16, pp. 2399-2409. DOI: 10.1016/j.jastp.2011.

Fang X., Randall C., Lummerzheim D., Solomon S.C., 
Electron impact ionization: A new parameterization for 100 eV to $1 \mathrm{MeV}$ electrons. J. Geophys. Res. 2008, vol. 113, A09311. DOI: 10.1029/2008JA013384.

Golikov I.A., Gololobov A.Yu., Popov V.I. Numerical simulation of thermal conditions of the high-latitude ionosphere. Vestnik Severo-Vostochnogo federal'nogo universiteta [Vestnik of North-Eastern Federal University]. 2012, vol. 9, no. 3, pp. 22-28. (In Russian).

Golikov I.A., Gololobov A.Yu., Popov V.I. Modeling the electron temperature distribution in F2 region of high-latitude ionosphere for winter solstice conditions. Solar-Terr. Phys. 2016, vol. 2, no. 4, pp. 70-80. DOI: 10.1029/GL009i009p00989.

Heppner J.P. Empirical model of high electric field. $J$. Geophys. Res. 1977, vol. 82, no. 7, pp. 1115-1125. DOI: 10.1029/ JA082i007p01115.

Klimenko V.V., Koren'kov Yu.N., Namgaladze A.A., Karpov I.V., Surotkin V.A., Naumova N.M. Numerical simulation of "hot spots" in the Earth's ionosphere. Geomagnetizm i aeronomiya [Geomagnetism and Aeronomy] 1991, vol. 31, no. 3, pp. 554-557. (In Russian).

Krymsky P.F. Azimuth currents and plasma heating in the vicinity of the plasmapause during disturbances. Geomagnet izm i aeronomiya [Geomagnetism and Aeronomy]. 1990, vol. 30, no. 5, pp. 747-752. (In Russian).

Kofman W. Very high electron temperature in the daytime F region at Sondrestrom. Geophys. Res. Lett. 1984, vol. 1, no. 9, pp. 912-922. DOI: 10.1029/GL011i009p00919.

Mingaleva G.I., Mingalev V.S. Manifestations of the effect of electron temperature increase in the main ionospheric trough due to internal processes in different seasons. Geomagnetizm i aeronomiya [Geomagnetism and Aeronomy]. 1992, vol. 32, no. 2, pp. 83-87. (In Russian).

Mingaleva G.I., Mingalev V.S. The formation of electron temperature hot spots in the main ionospheric trough by the internal processes. Ann. Geophys. 1996, vol. 15, no. 8, pp. 816-825. DOI: 10.1007/s00585-996-0816-x.
Picone J.M., Hedin A.E., Drob D.P., et al. NRLMSISE-00 empirical model of the atmosphere: Statistical comparison and scientific issues. J. Geophys. Res. 2002, vol. 107, no. A12, pp. 1501-1516. DOI: 10.1029/2002JA009430.

Prölls G.W. Subauroral electron temperature enhancement in the nighttime ionosphere. Ann. Geophys. 2006, vol. 25, no. 24 , pp. $1871-1885$.

Reigber C., Lühr H., Schwintzer P. CHAMP mission status. Adv. Space Res. 2002, vol. 30, pp. 129-134. DOI: 10.1016/S02 73-1177(02)00276-4.

Samarsky A.A. The theory of difference scheme. Moscow, Nauka Publ., 1977, 656 p. (In Russian).

Schunk R.W., Nagy A.F. Electron temperature in the F regions of the ionosphere: theory and observations. Rev. Geophys.: Space Phys. 1978, vol. 16, no. 3, pp. 355-399. DOI: 10.1029/RG $016 i 003 p 00355$.

Schunk R.W., Sojka J.J., Bowline M.D. Theoretical study of the electron temperature in the high-latitude ionosphere for solar maximum and winter conditions. J. Geophys. Res. 1986, vol. 91, no. 11, pp. 12041-12054. DOI: 10.1029/JA091iA11p12041.

Vorobjev V.G., Yagodkina O.I., Katkalov Yu.V. Auroral precipitation model and its applications to ionospheric and magnetospheric studies. J. Atmos. Solar-Terr. Phys. 2013, vol. 102, pp. 157-171. DOI: 10.1016/j.jastp.2013.05.007.

Xiong C., Lühr H., Ma S.Y. The subauroral electron density trough: Comparison between satellite observations and IRI-2007 model estimates. Adv. Space Res. 2013, vol. 51, no. 4, pp. 536-544. DOI: 10.1016/j.asr.2011.09.021.

URL: http://isdc-old.gfz-potsdam.de (accessed 8 August 2018).

How to cite this article

Gololobov A.Yu., Golikov I.A. Investigating seasonal features of electron temperature enhancement regions in the subauroral ionosphere. Solar-Terrestrial Physics. 2019. Vol. 5. Iss. 1. P. 62-68. DOI: $10.12737 /$ stp-51201909. 